\title{
From the Editor of Sexuality and Disability: Annual Acknowledgement and a Personalized Thank You
}

\author{
Sigmund Hough
}

Published online: 6 February 2014

(C) Springer Science+Business Media New York 2014

The journal of Sexuality and Disability wishes to thank the Editorial Board Members and Reviewers for their expertise and commitment during the year 2013. We welcome the addition of Editorial Board Members and Reviewers who will be joining us in 2014. As a professional team, your valued contributions to the journal and the field bring knowledge and resource to our readership and authorship. Your active participation and strategic presence is very much appreciated. We also wish to thank Springer Publishing and the dedicated staff that brings the journal into reality.

The beginning of a new year and opportunity. This issue brings exciting findings and thoughts to utilize and build upon. Still, more to do. Are you ready?

Sexuality and Disability continues to provide original impact articles addressing the mental health and medical aspects of sexuality in relation to rehabilitation, hospital, academic and community settings, publishing up-to-date articles, case studies, clinical practice reports, reviews, featured articles, historical articles, special grand rounds topics, brief research reports and survey data reports. Value benefit is provided to authors through worldwide electronic exposure and professional access, while readership gains from scholarly contributions to advance the field through research, best-practice and educational articles. The refined lens of individual contributions from the local and international community continues to deliver a wealth of information on the topic of sexuality and disability for the reader. Thank you for being a part of our professional network.

S. Hough $(\bowtie)$

396 Washington Street, Suite 211, Wellesley Hills, MA 02481, USA

e-mail: Sigmund_Hough@hms.harvard.edu 